\title{
The Antiperinuclear Factor and the So-called Antikeratin Antibodies Are the Same Rheumatoid Arthritis-Specific Autoantibodies
}

\author{
Mireille Sebbag, Michel Simon, Christian Vincent, Christine Masson-Bessière, Elisabeth Girbal, Jean-Jacques Durieux, \\ and Guy Serre \\ Department of Biology and Pathology of the Cell, Toulouse-Purpan School of Medicine, University of Toulouse III, \\ 31059 Toulouse, France
}

\section{Abstract}

The so-called antikeratin antibodies (AKA) and the antiperinuclear factor (APF) are the most specific serological markers of RA. Using indirect immunofluorescence, AKA label the stratum corneum of various cornified epithelia and APF the keratohyalin granules of human buccal mucosa epithelium. We recently demonstrated that $A K A$ recognize human epidermal filaggrin.

Here, we report the identification of the major APF antigen as a diffuse protein band of $200-400 \mathrm{kD}$. This protein is seen to be closely related to human epidermal (pro)filaggrin since it was recognized by four antifilaggrin $\mathrm{mAbs}$ specific for different epitopes, and since the APF titers of RA sera were found to be correlated to their AKA titers and to their immunoblotting reactivities to filaggrin. Immunoabsorption of RA sera on purified epidermal filaggrin abolished their reactivities to the granules of buccal epithelial cells and to the 200-400-kD antigen. Moreover, antifilaggrin autoantibodies, i.e., AKA, affinity purified from RA sera, were shown to immunodetect the 200-400-kD antigen and to stain these granules.

These results indicate that AKA and APF are largely the same autoantibodies. They recognize human epidermal filaggrin and (pro)filaggrin-related proteins of buccal epithelial cells. Identification of the epitopes recognized by these autoantibodies, which we propose to name antifilaggrin autoantibodies, will certainly open new paths of research into the pathophysiology of RA. (J. Clin. Invest. 1995. 95:2672-2679.) Key words: autoimmunity - autoantigen • keratohyalin granules $\bullet$ profilaggrin $\bullet$ antifilaggrin autoantibodies

\section{Introduction}

The hallmark of B cell involvement in the autoimmune pathophysiology of RA is the presence of various antibodies directed to self antigens in the sera of patients. Among them, rheumatoid factors have been the most extensively studied (reviewed in

Address correspondence to Guy Serre, Laboratoire de Biologie Cellulaire, C. H. U. Purpan, Place du Dr. Baylac, 31059 Toulouse Cedex, France. Phone: 33-61-77-23-95; FAX: 33-61-77-76-20. Mireille Sebbag's present address is Kennedy Institute of Rheumatology, Sunley Division, London, United Kingdom.

Received for publication 19 September 1994 and in revised form 28 December 1994.

J. Clin. Invest.

(C) The American Society for Clinical Investigation, Inc.

0021-9738/95/06/2672/08 \$2.00

Volume 95, June 1995, 2672-2679 reference 1), but numerous other autoantibodies such as anticollagen (2), antinuclear $(3,4)$, and anticytoskeletal (5) antibodies have been described. A lot of work has also been performed on the antiperinuclear factor (APF) ${ }^{1}(6-22)$ and on the antikeratin antibodies (AKA) $(9,21-37)$. Both these antibodies have been demonstrated to be highly specific serological markers of the disease and therefore are increasingly used for the diagnosis of RA (reviewed in reference 38 ).

AKA were identified by indirect immunofluorescence (IIF) in the serum of RA patients in 1979 by Young et al. (23). They label the stratum corneum, i.e., the cornified layer, of rat esophagus epithelium. Despite the lack of biochemical characterization of their target, the antibodies were called antikeratin, probably because cytokeratins constitute the major protein component of the stratum corneum. However, the IIF pattern of labeling produced by these antibodies was found to be unmodified by preabsorption of the RA sera with human cytokeratins (24) and we demonstrated that AKA differ from the naturally occurring autoantibodies to human epidermal cytokeratins (33). Recently, we identified the rat esophagus epithelium antigens defined by AKA as three noncytokeratin late differentiation proteins of $210,90-120$, and $60-130 \mathrm{kD}$ which had not been previously described (36). We also demonstrated that AKA label the stratum corneum of human epidermis and specifically recognize the $37-\mathrm{kD}$ basic epidermal filaggrin and its $40-\mathrm{kD}$ neutral/acidic isoform, and therefore are genuine autoantibodies (37). Filaggrin is an intermediate filament-associated protein involved in the aggregation of cytokeratin filaments during the cornification of the epidermis. It is synthesized in the stratum granulosum as a large and heavily phosphorylated precursor, profilaggrin, which is accumulated in keratinocyte-specific cytoplasmic organelles, the keratohyalin granules. During the late stages of epidermal keratinocyte differentiation, profilaggrin molecules are dephosphorylated and cleaved, to release functional filaggrin units (reviewed in reference 39 ).

Described in 1964 by Nienhuis and Mandema, APF corresponds to autoantibodies which, analyzed by IIF, label 0.5-7$\mu \mathrm{m}$-sized perinuclear granules in the superficial cells of human buccal mucosa epithelium (6). The APF-defined antigen has not been identified yet. However, the ultrastructural and histochemical properties of the granules $(8,17)$ and the sensitivity of APF assay to various enzymatic or chemical treatments of the cells (19) indicate that the granules correspond to keratohyalin granules and that the antigen is not composed of nucleic acids, but is rather a protein component sensitive to fixatives such as acetone and methanol and to freeze-thawing cycles.

An exhaustive survey of the literature allowed us to establish that APF and AKA share numerous features. AKA are clearly

1. Abbreviations used in this paper: AKA, antikeratin antibodies; APF, antiperinuclear factor; IIF, indirect immunofluorescence; p200-400, diffuse protein band with a mol wt of $200,000-400,000$. 
of IgG isotype (32) and APF has also been shown to be mainly of $\operatorname{IgG}$ isotype $(9,11)$. Both antibodies are very specific for RA: they occur with diagnostic sensitivities of 33-80 and 48$87 \%$ and diagnostic specificities of $87-100$ and $73-100 \%$, respectively (AKA: 9, 11, 22, 25-30; APF: 6-15, 17-19, 22). Their occurrence is independent of the age and sex of the patients $(6,16,30,31)$. Their presence and/or titers have been found to be correlated to each other $(9,19,21,22,38)$, to the presence of rheumatoid factors $(6,7,16,30)$, and to the severity and activity of the disease $(22,25-28,30,35)$. Furthermore, APF and AKA are both independent of the disease duration $(15,16,18,29,30)$, appear early, and may even precede the clinical manifestations of RA $(10,21,34,35)$. Lastly, both autoantibodies are detected in synovial fluid of RA patients (6, $17,18,24,28,31)$. Regarding this series of indirect arguments, it is tempting to speculate that APF and AKA are the same autoantibodies. Consistent with this hypothesis, the APF antigen could be related to filaggrin, the epidermal antigen recognized by AKA, because $(a)$ both antigens are expressed in epithelia of the same histologic type (rat esophagus epithelium, human epidermis, as well as human buccal epithelium are stratified squamous epithelia with similar programs of terminal differentiation) and ( $b$ ) the APF antigen has been reported (19) to colocalize with molecules reactive with AKH1, a (pro)filaggrin-specific mAb.

The goals of the present study were to immunologically and biochemically characterize the antigen recognized by APF in human buccal epithelial cells, and to provide direct immunological evidence of the identity between AKA and APF.

\section{Methods}

Human sera. RA sera were selected from a previously published series of 229 patients with classical or definite RA (33), according to the criteria of the American College of Rheumatology (40). In the series, AK A titers had been determined by IIF on cryosections of rat esophagus using a previously described and largely validated semiquantitative method $(30,33) .21$ RA sera, chosen with increasing AKA titer-like values ranging regularly along the semiquantitative scale $(0-8$, step 0.25 ) from 0.25 to 5.75 , were used in this study. Four non-RA human sera were used as negative controls.

Murine monoclonal antibodies. AKH1, an IgG1 murine mAb specific for human epidermal filaggrin and profilaggrin (41) was purchased from Biomedical Technologies Inc. (Stoughton, MA), as an ascitic fluid. AHF1, AHF2, AHF3, and AHF7, IgG1 murine mAbs directed to four different epitopes borne by filaggrin and/or not, profilaggrin ( $\mathrm{Si}$ mon, M., M. Sebbag, M. Haftek, C. Vincent, E. Girbal, J. Rakotoarivony, G. Sommé, and G. Serre, manuscript submitted for publication), were produced, characterized, and purified in our laboratory. 6B10, an IgG1 mAb directed to human cytokeratin No. 4 (42), was purchased from Sigma Chemical Co. (St. Louis, MO), as an ascitic fluid.

Indirect immunofluorescence on human buccal epithelial cells. Human buccal epithelial cells were obtained by scraping the inner side of the cheeks of three previously selected APF granule-positive donors. After four washes in ice-cold PBS, the cells were prepared by cytocentrifugation $\left(4 \times 10^{3}\right.$ cells $/$ slide) with a Cytospin (Shandon Inc., Runcorn, United Kingdom), air-dried for $15 \mathrm{~min}$, and stored at $4^{\circ} \mathrm{C}$ for a maximum of $24 \mathrm{~h}$. After a 15-min rehydration in PBS, the slides were incubated in a moist chamber for $90 \mathrm{~min}$ at $20^{\circ} \mathrm{C}$ with the human sera (diluted to $1: 5$ in PBS), AKH1 (1:100), AHF1 $(10 \mu \mathrm{g} / \mathrm{ml})$, or 6B10 (1:100). After two washes in PBS containing $0.05 \%$ Tween 20 and one wash in PBS alone, the slides were incubated for $30 \mathrm{~min}$ at room temperature with FITC-labeled goat Fab fragments to human $\gamma$ heavy chains of IgG (Biosys, Compiègne, France) or goat Ig to mouse IgG (Southern Biotechnology Associates, Birmingham, AL), both diluted to 1:50 in PBS. After washing as above, the slides were mounted with Fluoprep medium (Bio-Mérieux, Lyon, France) and observed with a $\mathrm{BH}_{2}$ microscope (Olympus Corp., Tokyo, Japan) with ultraviolet epiillumination. The method generally used for analysis of APF, subjectively evaluates the test as positive or negative, according to the presence of fluorescent granules in at least one cell. This is done either at one dilution or on a series of dilutions of the serum to allow a titration. It has been proposed to optimize this evaluation by assessing the percentage of cells labeled by the serum and considering as positive only the sera labeling $>10 \%$ of cells (18). Nevertheless, because of the large intra- and interindividual variations in the percentage of buccal cells that contain potentially immunoreactive perinuclear granules $(7,9,13,18,19)$, and to minimize the effects of this variability on the titration of sera, we used an original semiquantitative method for the evaluation of the APF titer. For each serum, 100 buccal cells were counted and the fluorescence intensity of each positive cell was scored on a scale from 0 to 5 (with 1-U steps). The mean fluorescence intensity of the positive cells gave a titer-like value that we considered as the APF titer. It is noteworthy that the APF titers we obtained were related for each donor to the percentage of positive cells.

Epithelial extracts. The antigens recognized by AKA, i.e., the three rat esophagus epithelium proteins and the $40 \mathrm{kD}$ neutral/acidic isoform of human epidermal filaggrin, were extracted and concentrated as previously described $(36,37)$. Briefly, rat esophagus epithelium was homogenized in $150 \mathrm{mM} \mathrm{NaCl}, 40 \mathrm{mM}$ Tris- $\mathrm{HCl}, \mathrm{pH} \mathrm{7.4}$, and the extracted proteins were precipitated in trichloroacetic acid and redissolved in distilled water. Human breast epidermis was lysed in the same buffer containing $0.5 \% \mathrm{NP}-40$ and the extracted proteins were precipitated in ethanol and redissolved in distilled water. As previously reported (37), this method gives rise to an extract enriched in the neutral/acidic isoform of filaggrin, a molecule with largely the same amino-acid composition and antigenicity as the basic filaggrin, but with a more acidic pI.

Human buccal epithelial cells were sequentially homogenized by vigorous agitation for $5 \mathrm{~min}$ with $200 \mu \mathrm{l}$ per $10^{6}$ cells of the following ice-cold buffers (three times in each buffer): $40 \mathrm{mM}$ Tris- $\mathrm{HCl}, \mathrm{pH} 7.4$, containing $150 \mathrm{mM} \mathrm{NaCl}, 10 \mathrm{mM}$ EDTA, $0.5 \% \mathrm{NP}-40,0.01 \%$ sodium azide, $2 \mu \mathrm{g} / \mathrm{ml}$ aprotinin and $1 \mathrm{mM}$ phenylmethylsulfonyl fluoride; then $20 \mathrm{mM}$ Tris- $\mathrm{HCl}, \mathrm{pH} 7.4$, containing $8 \mathrm{M}$ urea, $2 \mu \mathrm{g} / \mathrm{ml}$ aprotinin and 1 $\mathrm{mM}$ PMSF; lastly, the same buffer containing $0.1 \mathrm{M} \beta$-mercaptoethanol. After each extraction, the cell lysate was centrifuged for $10 \mathrm{~min}$ at $25,000 \mathrm{~g}$ and the supernatant removed. The three supernatants corresponding to the same buffer were pooled and the pools identified as $\mathrm{NP}-40$, urea, and urea- $\beta$-mercaptoethanol extract, respectively.

Gel electrophoresis. The rat esophagus epithelium extracts were separated by nondenaturing PAGE as previously described (43). Buccal epithelial cell proteins were precipitated with $4 \mathrm{vol}$ of ethanol (NP-40 extract) or acetone (urea and urea- $\beta$-mercaptoethanol extracts), and the precipitates were redissolved in $6 \mathrm{M}$ urea, $0.1 \mathrm{M} \beta$-mercaptoethanol, $4 \%$ SDS, $0.05 \%$ bromophenol blue, and $20 \mathrm{mM}$ Tris- $\mathrm{HCl}$, pH 6.8 (concentrated 10-fold for the NP-40 extract or 5-fold for the urea and urea$\beta$-mercaptoethanol extracts). Human epidermal and buccal epithelial extracts were separated by SDS-PAGE on $8-25$ and $4-15 \%$ polyacrylamide gradient gels, respectively, using the PhastSystem ${ }^{\mathrm{TM}}$ (Pharmacia LKB Biotechnology, Uppsala, Sweden), as described by the manufacturer. The molecular weight calibration kits were from Bio-Rad Laboratories (Richmond, CA) or Pharmacia LKB Biotechnology.

Immunoblotting. After electrophoresis, the rat esophagus or human buccal epithelial extracts were electrotransferred on nitrocellulose membranes (Bio-Rad Laboratories) and probed with human sera diluted to $1: 10$ or $1: 50$, respectively, as previously described (43). Human epidermal extracts were electrotransferred to reinforced nitrocellulose membranes (Schleicher \& Schuell, Inc., Dassel, Germany) and probed for $1 \mathrm{~h}$ at $20^{\circ} \mathrm{C}$ with human sera diluted to $1: 30$ in Tris- $\mathrm{HCl}, \mathrm{pH} 8$, containing $2 \mathrm{M} \mathrm{NaCl}$ and $0.05 \%$ Tween 20 . The blots were also probed with AKH1 (1:100) and the four AHF mAbs $(10 \mu \mathrm{g} / \mathrm{ml})$. Complexed IgG were visualized with peroxidase-labeled goat Fab fragments to human $\gamma$ heavy chains of IgG (Southern Biotechnology Associates) or sheep Fab fragments to mouse IgG (Biosys).

Purification of the neutral/acidic human epidermal filaggrin and immunoabsorption experiments. The neutral/acidic isoform of filaggrin 
was purified to homogeneity from the enriched human epidermal extract by affinity chromatography on a 2 -ml affinity column (CarboLink ${ }^{\mathrm{TM}}$; Pierce Chemical Co., Rockford, IL). 2 mg of periodate-oxidized anti(pro)filaggrin mAbs were bound to the column, as described by the manufacturer, in the following proportions: AHF1 (9.8\%), AHF2 (28.4\%), AHF3 (48.1\%), and AHF7 (13.7\%). The enriched human epidermal extract ( $200 \mu \mathrm{g}$ of proteins) was lyophilized, dissolved in PBS, and loaded onto the column. After incubation for $3 \mathrm{~h}$ at room temperature or overnight at $4^{\circ} \mathrm{C}$, the column was washed with $3 \mathrm{vol}$ of $1 \mathrm{M} \mathrm{NaCl}, 10 \mathrm{mM}$ phosphate buffer, $\mathrm{pH}$ 7.4. Bound filaggrin was eluted with $0.2 \mathrm{M}$ glycine- $\mathrm{HCl}, \mathrm{pH} 2.5$, and immediately neutralized by the addition of $0.05 \mathrm{vol}$ of $2 \mathrm{M}$ Tris base. About $100 \mu \mathrm{g}$ of pure filaggrin, as measured using the Coomassie Plus protein assay (Pierce Chemical Co.), were eluted from the column whereas no proteins were eluted from a control matrix prepared by binding $3.4 \mathrm{mg}$ of IgG purified from a pool of normal mouse sera (Sigma Chemical Co.). Eluted fractions were dialyzed against water and lyophilized.

For immunoabsorption, $1 \mu \mathrm{l}$ of undiluted RA serum or $2 \mu \mathrm{l}$ of mAb (ascitic fluid for AKH1 and $1 \mathrm{mg} / \mathrm{ml}$ solution of $\mathrm{mAbs}$ for the purified AHF) were incubated for $2 \mathrm{~h}$ at $4^{\circ} \mathrm{C}$ with $6 \mu \mathrm{g}$ of affinity-purified neutral/acidic filaggrin or BSA (Sigma Chemical Co.). They were then tested by IIF and immunoblotting as described above.

Purification of the human antifilaggrin autoantibodies. Antifilaggrin autoantibodies were purified from a pool of four RA sera with high titers of AKA, by affinity chromatography on an $N$-hydroxysuccinimideactivated affinity column (HiTrap ${ }^{\mathrm{TM}}$; Pharmacia LKB Biotechnology) ( $1 \mathrm{ml}$ ) coupled, as described by the manufacturer, with $500 \mu \mathrm{g}$ of the affinity-purified neutral/acidic human epidermal filaggrin. The column was loaded with $1 \mathrm{ml}$ of the pool diluted in $3 \mathrm{vol}$ of PBS. Washing and elution of bound antibodies were performed as described above. Affinity-purified antibodies were stored at $-20^{\circ} \mathrm{C}$ after the addition of BSA ( final concentration equal to $0.1 \mathrm{mg} / \mathrm{ml}$ ). The $\mathrm{IgG}$ activity of the eluted fractions was tested by IIF and immunoblotting, as described above. Two control experiments were performed. In the first, the same pool of RA sera was purified on a HiTrap ${ }^{\mathrm{TM}}$ affinity column coupled with 4 $\mathrm{mg}$ of BSA. In the second, a pool of two normal human sera was affinity purified on the column coupled with the neutral/acidic filaggrin.

Statistical analyses. Correlations were sought by computing Spearman's rank correlation coefficients.

\section{Results}

$A P F$ and $A K A$ titers are strongly correlated. The IIF reactivity of the 21 selected RA sera and of 2 control sera was analyzed on human buccal epithelial cells from three different donors. All the RA sera labeled cytoplasmic, mainly perinuclear, granules in a subpopulation of the buccal cells from the three donors whereas the control sera did not show any staining (Fig. $1 A$ ). The APF titers, semiquantitatively estimated, were similar and ranged identically whatever the donor was. The APF titers of the RA sera were found to be strongly correlated with their AKA titers previously determined by IIF on rat esophagus cryosections $(30,33)$. Fig. $1 B$ illustrates the APF titers determined with one of the donors (range 1-4.5) and their highly significant correlation with the AKA titers of the sera $(r=0.86, P$ $<10^{-6}$ ).

The reactivities of $R A$ sera to buccal keratohyalin granules and to the various AKA antigens are related. To compare the reactivities of RA sera to buccal keratohyalin granules and to the AKA antigens, the 2 control sera and 12 out of the 21 RA sera, chosen with APF titers ranging from low to high titer (1$4.5)$ and thus corresponding to the whole range of APF activities we determined above, were analyzed by immunoblotting on the neutral/acidic filaggrin enriched from a human epidermis extract and on proteins extracted from rat esophagus epithelium. The neutral/acidic filaggrin (Fig. $2 A$ ), specifically detected by
$A$

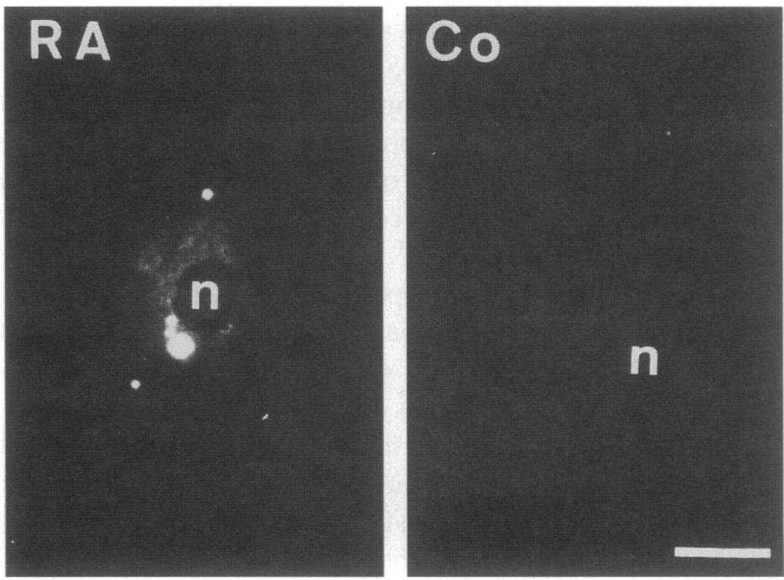

$B$

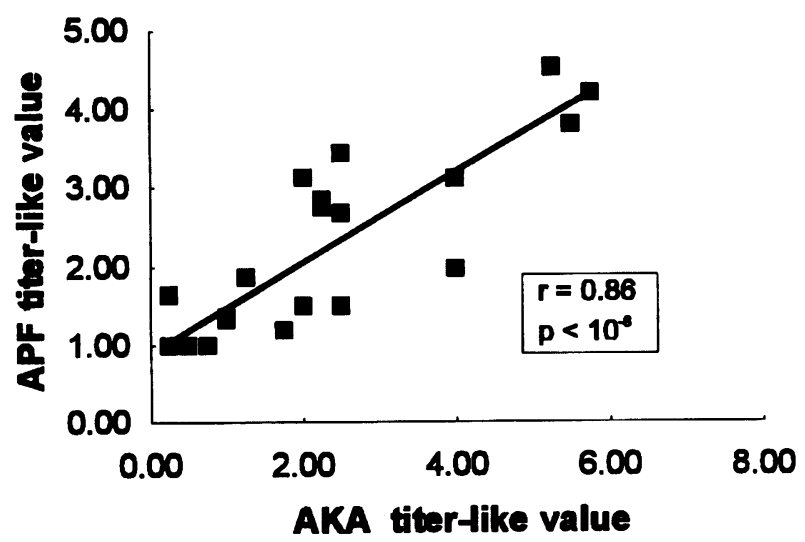

Figure 1. IIF pattern of labeling of APF and correlation of the APF and AKA titers in a series of 21 RA sera. (A) Typical immunofluorescence staining pattern produced by an APF-positive RA serum on buccal cells. Human buccal epithelial cells were collected by scraping the cheek of a positive donor, washed, spun down on microscope slides, and immunodetected with RA and control ( $\mathrm{Co}$ ) sera. The RA serum labels cytoplasmic perinuclear granules, whereas the control serum shows no staining. (B) Correlation between the titer-like values of APF and AKA, assessed as described in Methods. APF titer-like values correspond to one representative measurement out of three performed with cells from different donors. $r$, Spearman rank correlation coefficient; $\mathrm{n}$, nucleus; scale bar $=50 \mu \mathrm{m}$.

the anti-(pro)filaggrin mAbs AKH1 and AHF1, as previously published (37), was recognized by the nine RA sera with the highest APF titers. The three RA sera with the lowest APF titers and the two control sera did not stain the neutral/acidic filaggrin. Moreover, the immunoblotting reactivities of the sera towards human filaggrin were found to be correlated to their APF titers $\left(r=0.84, P<10^{-3}\right)$. In the rat esophagus epithelium extract (Fig. $2 B$ ), containing the $\mathrm{A}, \mathrm{B}$, and $\mathrm{C}$ protein antigens defined by AKA, all the tested sera reacted with the B protein. The higher staining intensities were observed with the nine RA sera showing the highest APF titers. Consistent with our previous results (43), A and C proteins were only detected by these 
A

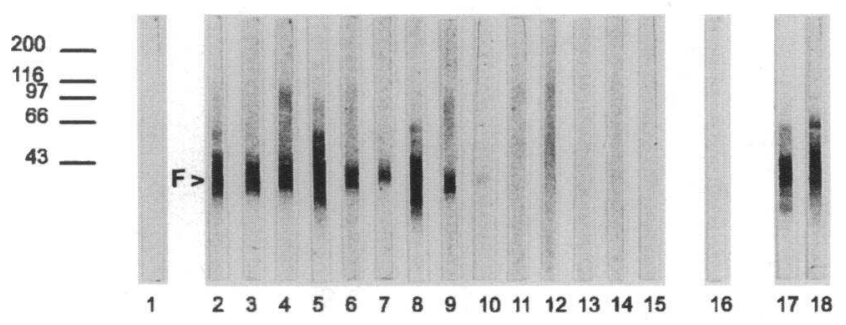

B

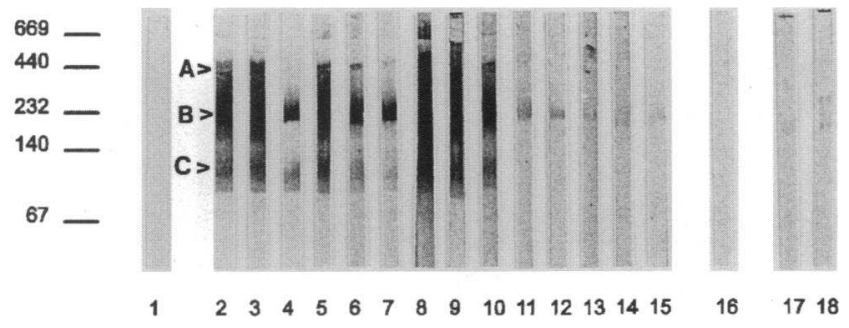

Figure 2. Immunoblotting detection of the AKA-specific antigens in human epidermal and rat esophagus epithelium extracts, by a series of 12 RA sera. The partially purified neutral/acidic isoform of human filaggrin $(A)$ and proteins from a low ionic-strength extract of rat esophagus epithelium $(B)$ were separated by SDS-PAGE or nondenaturing PAGE, respectively, on 8-25\% gradient gels and electrotransferred onto nitrocellulose membranes. Immunodetection was performed as follows: lanes 1 and 16 , control strips only incubated with peroxidaselabeled anti-human and anti-murine IgG, respectively; lanes 2-13, RA sera in decreasing order of APF titers; lanes 14 and 15 , control sera; lanes 17 and 18, anti-(pro)filaggrin mAbs AKH1 and AHF1. Arrowheads show the neutral/acidic variant of human epidermal filaggrin $(F)$, and the A, B, and C antigenic proteins of rat esophagus epithelium. Filaggrin is detected strongly by the eight RA sera with the highest APF titers (lanes 2-9), weakly by one RA serum (lane 10), but not by the RA sera with the lowest APF titers or by the control sera (lanes $11-15$ ). In the same way, the $A$ and $C$ proteins are only detected by the nine RA sera with the highest APF titers (lanes 2-10). The mAbs label human filaggrin but not the rat esophagus proteins. Note that the pattern of immunoblotting reactivity is more diffuse when the intensity of reactivity is higher. Migration of protein markers $\left(\times 10^{-3}\right.$ D) is indicated on the left.

nine RA sera. Furthermore, the APF titers of the sera were found to be correlated to their immunoblotting reactivities to the A $(r=0.74, P<0.003)$, B $(r=0.75, P<0.002)$, and $\mathrm{C}(r=0.76, P<0.002)$ proteins. The mAbs to human (pro)filaggrin did not stain the $\mathrm{A}, \mathrm{B}$, or $\mathrm{C}$ proteins.

Identification of the APF antigen in human buccal epithelial cell extracts. To identify the antigens recognized by APF, buccal epithelial cells from the three donors were sequentially extracted with Tris- $\mathrm{HCl}$ buffers containing NP-40, urea, and finally urea and $\beta$-mercaptoethanol. After concentration, the extracted proteins were separated by SDS-PAGE, electrotransferred onto nitrocellulose, and immunodetected with the 2 control sera and the 12 selected RA sera.

In the NP-40 extract (Fig. 3), a diffuse protein band with an apparent mol wt of 200,000-400,000 (p200-400), even spreading on down to 150,000 with the highly reactive sera, was specifically stained by 9 out of the 12 RA sera but was not detected by the control sera. Interestingly, the three RA sera

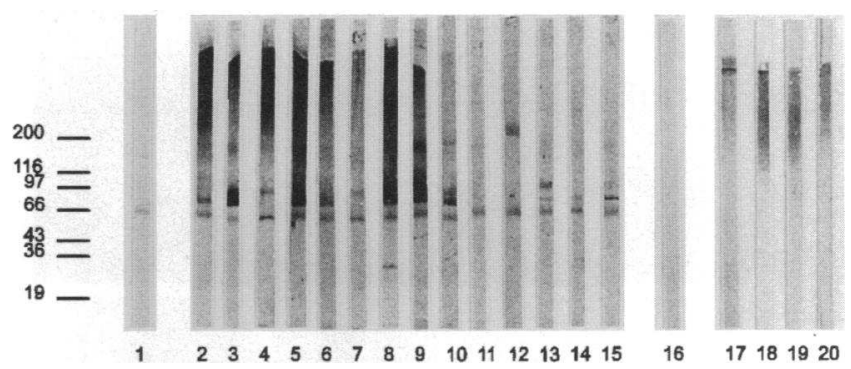

Figure 3. Immunoblotting detection of the APF antigen in a human buccal epithelial cell extract, by a series of 12 RA sera. Human buccal epithelial cells were lysed in Nonidet P-40 containing Tris buffer, and proteins were concentrated by ethanol precipitation, separated by SDSPAGE on 4-15\% gradient gel, and electrotransferred onto nitrocellulose membranes. Immunodetection was performed as follows: lanes 1 and 16, control strips only incubated with peroxidase-labeled anti-human or anti-murine IgG, respectively; lanes 2-13, RA sera in decreasing order of APF titers; lanes 14 and 15, control sera; lanes 17-20, anti(pro)filaggrin mAbs AKH1, AHF1, AHF2, and AHF7. A diffuse protein band with apparent mol wt of 200,000-400,000 (even spreading on down to 150,000 with the highly reactive sera) is specifically detected by the nine RA sera showing the highest APF titers, with a strong (lanes 2-9) or a weak (lane 10) reactivity. A similar diffuse band is also recognized by the four anti-(pro)filaggrin mAbs. Note that all the sera, including the controls, detect additional bands unrecognized by the mAbs. This result corresponds to one representative experiment out of three, performed with cell extracts from different donors.

which did not detect p200-400 had the lowest APF titer (=1.0). The nine RA sera, reactive to p200-400 in NP-40 extracts, also labeled a poorly resolved band with the same relative mobility in the urea- $\beta$-mercaptoethanol extract, but not in the urea extract (not shown). Furthermore, the staining intensities of p200-400 by the RA sera were found to be correlated to their APF titers $\left(r=0.79, P<10^{-3}\right)$. The data suggest that p200-400 is the major antigen recognized by RA sera in the perinuclear granules of buccal epithelial cells.

It should be noted that all the sera, including the two controls, detected additional sharp polypeptide bands, including contaminant human IgG heavy chains also detected by the secondary antibody, in the NP-40 extract (Fig. 3). Additional proteins were also nonspecifically detected in urea and urea- $\beta$ mercaptoethanol extracts (not shown).

To test whether p200-400 was related to filaggrin and/or its precursor, the buccal epithelial cell proteins were immunodetected with various (pro)filaggrin-specific mAbs. The four mAbs, AKH1, AHF1, AHF2, and AHF7 also recognized a diffuse protein band of $200-400 \mathrm{kD}$ in the NP-40 extract (Fig. 3 ) and in the urea- $\beta$-mercaptoethanol extract, but did not recognize any protein in the urea extract (not shown). AHF7, which does not recognize epidermal profilaggrin, presented the same labeling pattern as the other mAbs.

Immunoabsorption of APF with the neutral/acidic filaggrin. The correlations between APF and AKA titers and the immunoblotting data suggested that APF and AKA might have the same specificity. To further investigate the relationship between the two autoantibodies, four RA sera with high titers of AKA and APF were absorbed on the neutral/acidic isoform of human filaggrin, affinity purified to homogeneity as judged by Coomassie blue staining and immunoblotting analysis (data not shown). The inhibition of the AKA reactivity was checked by testing the absorbed RA sera using IIF on cryosections of rat esophagus 

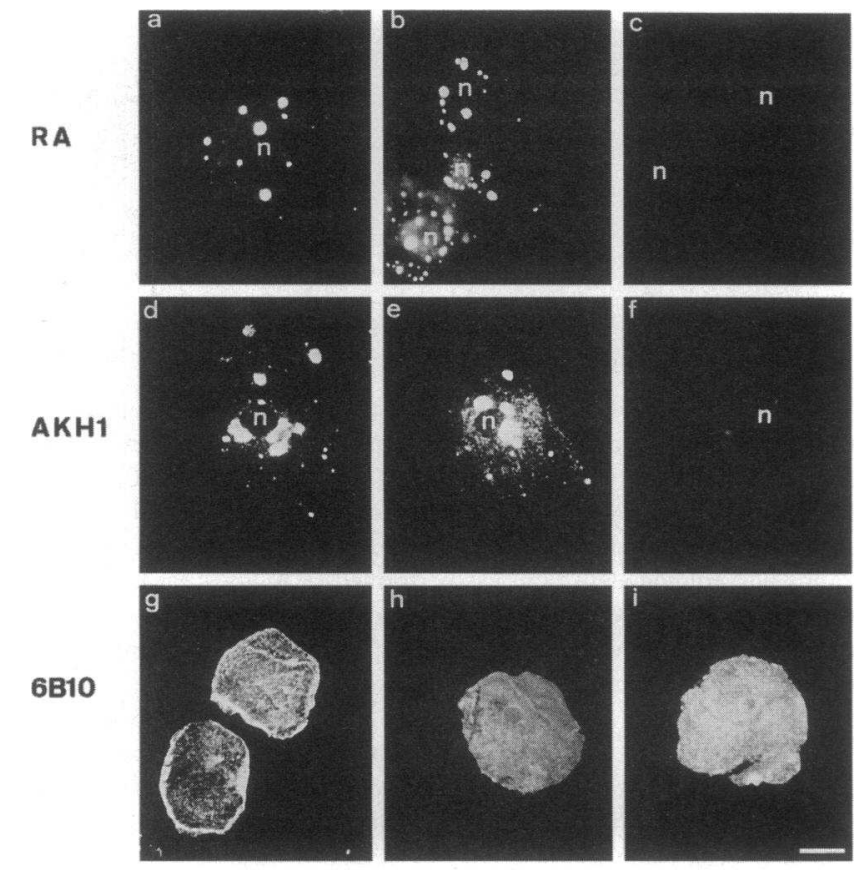

BSA

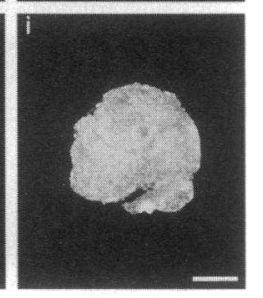

FIL

Figure 4. IIF pattern of labeling produced on human buccal epithelial cells by RA sera and mAbs immunoabsorbed on purified neutral/acidic epidermal filaggrin. One RA serum with a high APF titer $(a-c)$ and the mAbs AKH1 directed to human (pro) filaggrin $(d-f)$ and 6B10 directed to human cytokeratin No. 4 ( $g-i)$ were analyzed by IIF on human buccál epithelial cells, before $(a, d$, and $g ;-)$ and after immunoabsorption with BSA $(b, e$, and $h)$ or with the affinity-purified neutral/ acidic filaggrin $(c, f$, and $i ; F I L)$. With or without incubation with BSA, the serum and AKH1 show a typical intense labeling of the perinuclear granules, whereas 6B10 shows a diffuse cytoplasmic labeling. Immunoabsorption with purified filaggrin induces an extinction of the granule labeling produced by the RA serum and by $\mathrm{AKH} 1$, but does not modify the staining produced by $6 \mathrm{~B} 10$. Identical inhibitions were obtained with three other RA sera and with the mAb AHF1. Scale bar $=50 \mu \mathrm{m}(a-$ $f)$ or $100 \mu \mathrm{m}(g-i) ; \mathrm{n}$, nucleus.

and using immunoblotting on human epidermal and rat esophagus epithelial extracts. As previously published (37), significant inhibition of the fluorescence intensity on the stratum corneum of the rat esophagus epithelium, and of the immunoblotting reactivity to the neutral/acidic isoform of epidermal filaggrin was observed. In addition, inhibition of the immunoblotting reactivity to the three rat epithelial proteins was also observed. In a control test, no decrease in the staining intensities occurred after absorption of the RA sera on BSA.

The four immunoabsorbed sera were then assayed by IIF on buccal epithelial cells (Fig. 4, $a-c$ ) and by immunoblotting on the NP-40 and urea- $\beta$-mercaptoethanol extracts of buccal epithelial cells (Fig. 5, $A$ and $B$ ). After absorption on the purified neutral/acidic human filaggrin, the immunofluorescence reactivity of the sera to the buccal granules was either drastically decreased (two sera) or abolished. Likewise, the immunoblotting reactivity of the four immunoabsorbed sera to p200-400 was completely abolished. The inhibition by the neutral/acidic filaggrin of both the reactivities was specific because it was not reproduced by immunoabsorption on BSA and because the nonspecific immunoblotting reactivity of the sera toward additional bands was unchanged after the immunoabsorption on
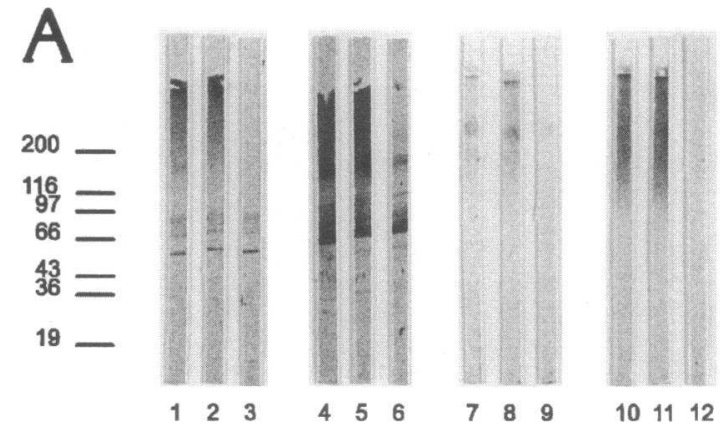

$\begin{array}{lll}7 & 8 & 9\end{array}$

101112
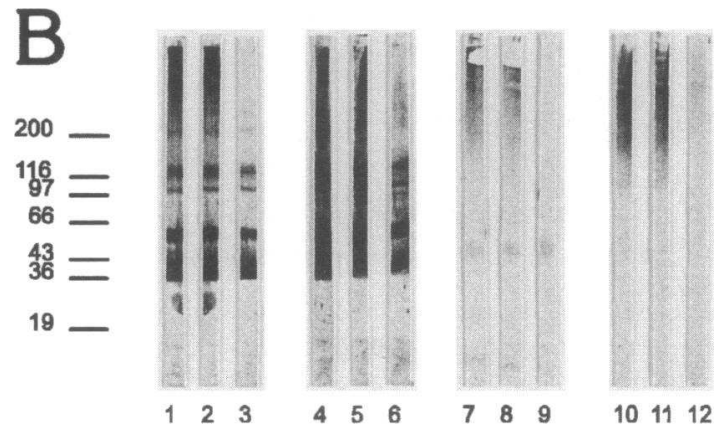

Figure 5. Immunoblotting detection of human buccal epithelial cell extracts by RA sera and mAbs immunoabsorbed on purified neutral/ acidic epidermal filaggrin. Proteins of the NP-40 $(A)$ and urea- $\beta$-mercaptoethanol $(B)$ extracts of human buccal epithelial cells were separated by SDS-PAGE on 4-15\% gradient gels and electrotransferred onto nitrocellulose membranes. Immunoblotting analysis was performed with two RA sera with high APF titers (lanes 1-3 and 4-6, respectively), and the two mAbs to human (pro)filaggrin AKH1 (lanes 7-9) and AHF1 (lanes 10-12), which had been previously incubated alone (lanes 1, 4, 7, and 10), with BSA (lanes 2, 5, 8, and 11), or with affinity-purified neutral/acidic filaggrin (lanes 3, 6, 9, and 12). Preincubation with filaggrin inhibits the immunoreactivity of the sera and of the mAbs towards p200-400, whereas preincubation with BSA does not. Note that preincubation with filaggrin does not modify the immunoreactivity of the sera toward the additional bands.

filaggrin. Similarly, the IIF and immunoblotting reactivities of the anti-(pro)filaggrin mAbs AKH1 and AHF1 were completely and specifically inhibited after immunoabsorption on the neutral/acidic filaggrin (Fig. $4, d-f$ and Fig. 5, $A$ and $B$ ). In a control test, filaggrin did not inhibit the binding of the filaggrinunreactive mAb 6B10 which is directed against cytokeratin No. 4 , a protein specific of noncornified squamous epithelia (Fig. $4, g-i)$.

Affinity purification of APF on the neutral/acidic filaggrin. To confirm the large identity of APF and AKA, antifilaggrin autoantibodies were affinity purified from a pool of four RA sera with high titers of APF and AKA, by chromatography on a column of immobilized neutral/acidic filaggrin. The specificity of the binding to human epidermal filaggrin and to rat esophagus antigens by the purified autoantibodies was checked by immunoblotting on crude epidermal extracts of human epidermis and rat esophagus epithelium (not shown). Analyzed by IIF on cryosections of rat esophagus and human skin, the autoantibodies exclusively stained the stratum corneum of the rat esophagus epithelium and human epidermis. Moreover, the anti- 

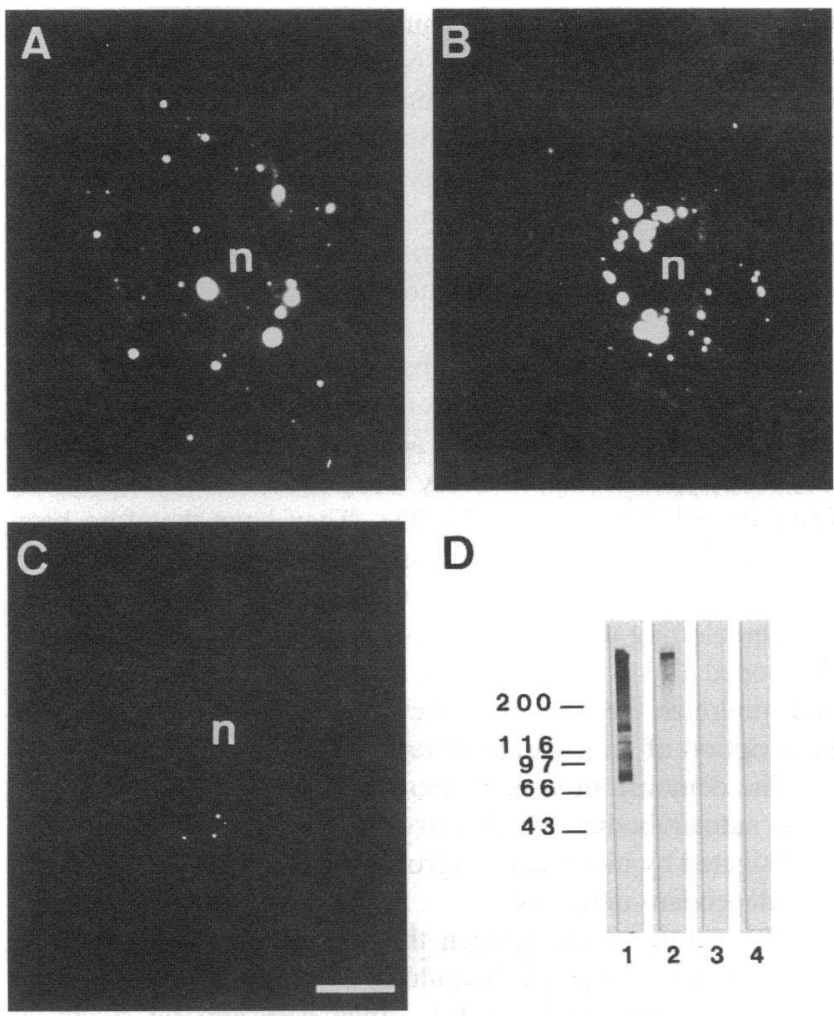

Figure 6. IIF and immunoblotting analysis of affinity-purified antifilaggrin autoantibodies. A pool of four RA sera and a pool of two normal sera were affinity purified on the purified neutral/acidic epidermal filaggrin or on BSA and the eluates were tested by IIF on human buccal epithelial cells $(A-C)$ and by immunoblotting on the NP-40 extract of these cells $(D) .(A)$ The pool of RA sera, diluted to $1: 5$, produces the typical intense labeling of the perinuclear granules. $(B$ ) Antifilaggrin autoantibodies, affinity purified from this pool of RA sera and used diluted to 1:2, produce the same labeling of the buccal cells. $(C)$ Antibodies, affinity purified from the same pool of RA sera on BSA and used undiluted, show no labeling of the buccal cells. $(D)$ The pool of RA sera immunodetects p200-400 and additional epithelial proteins (lane 1 ) whereas the antifilaggrin autoantibodies exclusively immunodetect p200-400 (lane 2). The anti-BSA antibodies (lane 3) and autoantibodies affinity purified on filaggrin from the pool of control sera (lane 4) do not immunodetect any protein. Scale bar $=50 \mu \mathrm{m}$; n, nucleus.

bodies affinity purified from the same pool of RA sera on BSA, and the antibodies affinity purified from a pool of two control sera on human filaggrin, did not show any reactivity to the tissues, confirming that AKA reactivity is confined in antifilaggrin autoantibodies (44).

The antifilaggrin autoantibodies, affinity purified from the pool of RA sera, were then tested for their APF activity. They produced an intense staining of the perinuclear granules of human buccal epithelial cells, similar to that produced by the pool. Conversely, the antibodies affinity purified from the same pool of RA sera on BSA, and the antibodies affinity purified from the pool of control sera on human filaggrin did not label the perinuclear granules (Fig. 6, $A-C$ ). When tested by immunoblotting, the purified antifilaggrin autoantibodies labeled a diffuse protein band of $200-400 \mathrm{kD}$ that largely comigrated with p200-400 in the NP-40 extract of human buccal epithelial cells. No staining of additional bands was observed. The control eluates of the same pool of RA sera purified on BSA and of the normal sera purified on neutral/acidic filaggrin did not show any reactivity (Fig. $6 \mathrm{D}$ ). These results provide further convincing evidence that APF and AKA present the same antifilaggrin specificity.

\section{Discussion}

$30 \mathrm{yr}$ after the initial report of Nienhuis and Mandema (6), our study provides the first biochemical characterization of the major antigen recognized by APF in the perinuclear keratohyalin granules of human buccal epithelial cells. On immunoblots, RA sera reproducibly recognized a diffuse protein band with an apparent mol wt of 200,000-400,000 (p200-400) extracted from cells of three different donors. This protein was detected neither by non-RA sera nor by RA sera with the lowest APF activity. In addition, the staining intensities of p200-400 by the RA sera were found to be correlated to their APF titers detected by IIF. These data strongly suggest that p200-400 is the antigen recognized by APF in the perinuclear granules of human buccal epithelial cells. This is confirmed by immunoabsorption experiments, since both the reactivities to the perinuclear granules and to $200-400$ were specifically inhibited after immunoabsorption of APF-positive RA sera on purified epidermal filaggrin. The uncomplete absorption of the APF reactivities observed with some RA sera either suggests the existence of other minor APF-recognized antigens or more likely indicates that discontinuous or conformational epitopes present in situ on p200-400 are absent on the purified filaggrin.

Moreover, p200-400 was also recognized by four mAbs specific for different epitopes of human epidermal (pro)filaggrin. This close immunological relationship with (pro)filaggrin suggests a close biochemical relationship. Consistent with this, is the previous observation by IIF that (pro) filaggrin colocalizes on the buccal cell keratohyalin granules with the antigen recognized by APF (19). In the same way, all the seven AHF mAbs we have produced against human epidermal (pro)filaggrin, label the perinuclear granules of human buccal epithelial cells (Sebbag, M., M. Simon, C. Vincent, C. Masson-Bessière, E. Girbal, J.-J. Durieux, and G. Serre, unpublished observations ) These data, together with the absence of detectable $37-\mathrm{kD}$ basic, as well as neutral/acidic, isoforms of filaggrin in buccal epithelial cells (reference 45 and our results), suggest that p200-400, because of its high molecular weight, is the filaggrin precursor, profilaggrin. In agreement, epidermal profilaggrin usually migrates on SDS-gel as a diffuse band (39). However, p200-400 differs from epidermis profilaggrin in some respects. First, after sequential extraction of proteins from buccal epithelial cells, p200-400 was detected in NP-40 and urea- $\beta$-mercaptoethanol, but not in the urea extracts. Conversely, profilaggrin is known to be present in urea but not in NP-40 sequential extracts of human epidermis. Secondly, RA sera, analyzed by IIF and immunoelectron microscopy on human skin, do not label the profilaggrin-containing keratohyalin granules of the epidermis and, in immunoblotting, do not recognize human epidermal profilaggrin (44). Similarly, the filaggrin-specific mAb AHF7 does not label the keratohyalin granules of human epidermis and does not detect profilaggrin on immunoblots (Simon, M., M. Sebbag, M. Haftek, C. Vincent, E. Girbal, J. Rakotoarivony, G. Sommé, and G. Serre, manuscript submitted for publication). In contrast, both the RA sera and AHF7 labeled perinuclear granules in buccal epithelial cells and recognized p200-400 on immunoblots. This p200-400 antigen may consist of processed filaggrin covalently linked with other cellular proteins. This is unlikely because $(a)$ such a complex resistant to urea, SDS, 
and $\beta$-mercaptoethanol has never been described in epidermal cells, and $(b)$ mature filaggrin is not expressed in buccal cells. More likely, these differences between epidermal profilaggrin and p200-400 may be due to a differential processing of the filaggrin precursor in cornified and noncornified squamous epithelia. p200-400 may correspond to partially dephosphorylated profilaggrin and partial or complete dephosphorylation of profilaggrin, associated or not to its cleavage into filaggrin units, may be necessary for its recognition by RA sera in the filaggrincontaining matrix of corneocytes in the stratum corneum of human epidermis, as well as in the perinuclear granules of human buccal epithelial cells. This later hypothesis also may explain how the expression of profilaggrin can be induced by exposure of cultured human buccal epithelial cells to $12-\mathrm{O}$ tetradecanoylphorbol-13-acetate while the expression of the antigen recognized by APF cannot (20). Moreover, intra- and interindividual variations in the partial processing of profilaggrin in buccal cells, perhaps related to fine variations in the expression of the differentiation program of the buccal epithelium, could explain the large intra- and interindividual variations in the expression of the APF antigen $(7,9,13,19)$.

Hoet and co-workers recently failed to identify any protein from buccal epithelial cells that was immunoreactive with APFpositive RA sera (19). This discrepancy with our results may simply reflect differences in sensitivity of the immunoblotting assays. Alternatively, p200-400 could have been extracted by washings of the buccal cells in the presence of detergent as performed by these authors before immunoblotting analysis. To elucidate this discrepancy, we prepared and analyzed by immunoblotting, protein extracts of buccal epithelial cells from two different donors, according to Hoet et al. (19). Consistent with the first assumption and with the results described above, the sera with high APF titers and the anti-(pro)filaggrin mAbs reacted with a diffuse band of $200-400 \mathrm{kD}$ in these extracts. In addition, these reactivities were found to be inhibited by a preincubation of the sera with affinity-purified neutral/acidic epidermal filaggrin (data not shown).

The close relationship between p200-400 (the APF antigen) and filaggrin (the AKA antigen), suggests that APF and AKA are the same autoantibodies, as has been previously supposed $(21,38)$. The strong correlation between the APF and AKA titers that we observed and the series of indirect bioclinical arguments already reviewed (see Introduction) are in agreement with this hypothesis. Furthermore, when we tested the RA sera by immunoblotting on the various known AKA antigens, i.e., the $\mathrm{A}, \mathrm{B}$, and $\mathrm{C}$ rat esophagus epithelial proteins and human epidermal filaggrin, the intensities of labeling of these proteins were found to be correlated to the APF titers of the sera, suggesting that the intensity of the immune responses parallel each other. To ensure that APF and AKA had the same specificity, some RA sera with a high APF titer were incubated with the affinity-purified neutral/acidic epidermal filaggrin. The immunoabsorbed RA sera showed a large decrease in their AKA activity and lost their reactivity to the perinuclear granules of buccal epithelial cells and to p200-400. This absorption, specifically produced by filaggrin and not by the control protein BSA, strongly suggests that APF recognizes filaggrin as AKA do. Alternatively, the loss of APF activity may be due to hindrance of the epitopes on the APF antigen or to an alteration of the autoantibody by filaggrin. To rule out these possibilities, antifilaggrin autoantibodies were affinity purified from a pool of RA sera. The purified autoantibodies maintained both the APF and AKA specificities of the whole serum pool when tested by IIF as well as by immunoblotting. Taken together, these data demonstrate that AKA and APF correspond to identical or at least largely overlapping populations of autoantibodies which we propose to name antifilaggrin autoantibodies, abbreviated AFA. Whether the epitopes recognized by APF on the perinuclear granules of human buccal epithelial cells are all borne by the stratum corneum of human epidermis and rat esophagus epithelium remains to be explored in a larger series of RA sera.

Both APF and AKA have been shown to be the most specific serological markers of RA $(6-15,17-19,22,25-30)$, to correlate with the severity and activity of the disease $(22,25$ $28,30,35$ ), and to appear early, even before the clinical manifestations of RA $(10,21,34,35)$. They have therefore been proposed, and are increasingly used, as serological markers for the diagnosis of RA (30). The use of a sensitive and reliable immunoblotting test for their detection, as the one we recently developed (43), should facilitate the early diagnosis of RA and minimize the time spent between symptom onset and the prescription of an accurate therapy (46).

The demonstration made here, that APF and AKA are the same autoantibodies, gathers two fields of research about RA, investigated by more than 15 groups since 1964 and considered as independent until now.

The nature of the antigen that drives the antifilaggrin response is not yet known. It could be involved in the onset and/ or the pathophysiology of RA, since APF and AKA appear before its clinical manifestations. In keeping with our results, it would be tempting to speculate that filaggrin is this antigen. However, filaggrin is not considered to be expressed by synoviocytes or chondrocytes. Alternatively, the AFA-inducing antigen may be a cross-reactive molecule expressed by these cells. Therefore, we are now searching for such an autoantigen in synovial joints of RA patients. Characterization of the epitopes defined by AFA on filaggrin and on a hypothetical articular autoantigen might help to elucidate RA etiology and open the way toward preventive and/or specific immunosupressive therapeutics.

\section{Acknowledgments}

We thank Professors A. Fournié and B. Fournié (Clinique de Rhumatologie, Hôpital Purpan, Toulouse, France); Professors B. Mazières and A. Cantagrel (Service de Rhumatologie, Hôpital Rangueil, Toulouse, France) for providing patient data and sera. We also thank Professor $\mathbf{M}$. Costagliola (Service de Chirugie Plastique, Hôpital Rangueil, Toulouse, France) for providing samples of human skin. The technical assistance of M.-P. Cazevieille, M.-F. Isaia, and C. Pons is gratefully acknowledged.

This study was supported by grants from the Fondation pour la Recherche Médicale, the Association pour la Recherche sur la Polyarthrite, the Institut National de la Santé et de la Recherche Médicale (CRE-93-0205), and the Région Midi-Pyrénées.

\section{References}

1. Carson, D. A. 1989. Rheumatoid factor. In Textbook of Rheumatology. W. N. Kelley, E. D. Harris, Jr., S. Ruddy, and C. B. Sledge, editors. W. B. Saunders Co., Philadelphia. 198-207.

2. Terato, K., Y. Shimozuru, K. Katayama, Y. Takemitsu, I. Yamashita, M. Miyatsu, K. Fujii, M. Sagara, S. Kobayashi, M. Goto, et al. 1990. Specificity of antibodies to type II collagen in rheumatoid arthritis. Arthritis Rheum. 33:14931500.

3. Steiner, G., K. Hartmuth, K. Skriner, I. Maurer-Fogy, A. Sinski, E. Thalmann, W. Hassfeld, A. Barta, and J. S. Smolen. 1992. Purification and partia sequencing of the nuclear autoantigen RA33 shows that it is indistinguishable 
from the A2 protein of the heterogeneous nuclear ribonucleoprotein complex. $J$. Clin. Invest. 90:1061-1066.

4. Tuaillon, N., S. Muller, J.-L. Pasquali, P. Bordigoni, P. Youinou, and M. H. V. Van Regenmortel. 1990. Antibodies from patients with theumatoid arthritis and juvenile chronic arthritis analyzed with core histone synthetic peptides. Int. Arch. Allergy Appl. Immunol. 91:297-305.

5. Senécal, J. L., J. M. Oliver, and N. Rothfield. 1985. Anticytoskelatal autoantibodies in the connective tissue diseases. Arthritis Rheum. 258:889-897.

6. Nienhuis, R. L. F., and E. Mandema. 1964. A new serum factor in patients with rheumatoid arthritis: the antiperinuclear factor. Ann. Rheum. Dis. 23:302305 .

7. Sondag-Tschroots, I. R. J. M., C. Aaij, J. W. Smit, and T. E. W. Feltkamp. 1979. The antiperinuclear factor. 1 . The diagnostic significance of the antiperinuclear factor for theumatoid arthritis. Ann. Rheum. Dis. 38:248-251.

8. Smit, J. W., I. R. J. M. Sondag-Tschroots, C. Aaij, T. E. W. Feltkamp, and T. M. Feltkamp-Vroom. 1980. The antiperinuclear factor. 2. A light microscopical and immunofluorescence study on the antigenic substrate. Ann. Rheum. Dis. 39:381-386

9. Johnson, G. D., A. Carvalho, E. J. Holborrow, D. H. Goddard, and G. Russell. 1981. Antiperinuclear factor and keratin antibodies in theumatoid arthritis. Ann. Rheum. Dis. 40:263-266.

10. Scherbaum, W. A., P. Y. Youinou, P. Le Goff, and G. F. Bottazzo. 1984. Antiperinuclear and rheumatoid factor in different forms of autoimmune thyroid disease. Clin. Exp. Immunol. 55:516-518.

11. Kataaha, P. K., S. M. Mortazavi-Milani, G. Russell, and E. J. Holborow. 1985. Anti-intermediate filament antibodies, antikeratin antibody, and perinuclear factor in rheumatoid arthritis and infectious mononucleosis. Ann. Rheum. Dis. 44:446-449.

12. Westgeest, A. A. A., A. M. T. Boerbooms, M. Jongmans, J. P. Vandenbroucke, G. Vierwinden, and L. B. A. van de Putte. 1987. Antiperinuclear factor: indicator of more severe disease in seronegative rheumatoid arthritis. J. Rheuma tol. 14:893-897.

13. Janssens, X., E. M. Veys, G. Verbruggen, and L. Declercq. 1988. The diagnostic significance of the antiperinuclear factor for theumatoid arthritis. $J$. Rheumatol. 15:1346-1350.

14. Hoet, R. M., R. Zewald, and W. J. van Venrooij. 1989. Two highly specific antigens for rheumatoid arthritis. Clin. Rheumatol. 8:131a (Abstr.).

15. Boerbooms, A. M. T., A. A. A. Westgeest, P. Reekers, and L. B. A. van de Putte. 1990. Immunogenetic heterogeneity of seronegative theumatoid arthritis and the antiperinuclear factor. Ann. Rheum. Dis. 49:15-17.

16. Saraux, A., P. Fauquert, P. Youinou, and P. Le Goff. 1990. What does a titer of antiperinuclear factor above 1/5000 mean? Clin. Exp. Rheumatol. 8:130a (Abstr.)

17. Vivino, F. B., and G. G. Maul. 1990. Histologic and electron microscopic characterization of the antiperinuclear factor antigen. Arthritis Rheum. 33:960969.

18. Youinou, P., P. Le Goff, A. Dumay, A. Lelong, P. Fauquert, and J. Jouquan. 1990. The antiperinuclear factor. I. Clinical and serologic associations. Clin. Exp. Rheumatol. 8:259-264.

19. Hoet, R. M., A. M. T. Boerbooms, M. Arends, D. J. Ruiter, and W. J. van Venrooij. 1991. Antiperinuclear factor, a marker autoantibody for rheumatoid arthritis: colocalisation of the perinuclear factor and profilaggrin. Ann. Rheum. Dis. 50:611-618.

20. Hoet, R. M., A. C. A. Voorsmit, and W. J. van Venrooij. 1991. The perinuclear factor, a rheumatoid arthritis-specific autoantigen, is not present in keratohyalin granules of cultured buccal mucosa cells. Clin. Exp. Immunol. 84:5965 .

21. Aho, K., R. von Essen, P. Kurki, T. Palosuo, and M. Heliövaara. 1993. Antikeratin antibody and antiperinuclear factor as markers for subclinical rheumatoid disease process. J. Rheumatol. 20:1278-1281.

22. von Essen, R., P. Kurki, H. Isomäki, S. Okubo, H. Kantiainen, and K. Aho. 1993. Prospect for an additional laboratory criterion for theumatoid arthritis. Scand. J. Rheumatol. 22:267-272.

23. Young, B. J. J., R. K. Mallya, R. D. G. Leslie, C. J. M. Clark, and T. J. Hamblin. 1979. Anti-keratin antibodies in rheumatoid arthritis. Br. Med. J. 2:9799.

24. Quismorio, F. P., R. L. Kaufman, Jr., T. Beardmore, and S. Mongan. 1983. Reactivity of serum antibodies to the keratin layer of rat esophagus in patients with rheumatoid arthritis. Arthritis Rheum. 26:494-499.

25. Mallya, R. K., B. J. J. Young, M. B. Pepys, T. J. Hamblin, B. E. W Mace, and E. B. D. Hamilton. 1983. Anti-keratin antibodies in rheumatoid arthritis: frequency and correlation with other features of the disease. Clin. Exp. Immunol. 51:17-20.
26. Ordeig, J., and J. Guardia. 1984. Diagnostic value of antikeratin antibodies in rheumatoid arthritis. J. Rheumatol. 11:602-604.

27. Hajiroussou, V. J., J. Skingle, A. P. Gillett, and M. Webley. 1985. Significance of antikeratin antibodies in rheumatoid arthritis. J. Rheumatol. 12:57-59.

28. Youinou, P., P. Le Goff, C. B. Colaco, J. Thivolet, D. Tater, J. Viac, and M. Shipley. 1985. Antikeratin antibodies in serum and synovial fluid show specificity for rheumatoid arthritis in a study of connective tissue diseases. Ann. Rheum. Dis. 44:450-454.

29. Kirstein, H., and F. K. Mathiesen. 1987. Antikeratin antibodies in rheumatoid arthritis. Methods and clinical significance. Scand. J. Rheumatol. 16:331337.

30. Vincent, C., G. Serre, F. Lapeyre, B. Fournié, C. Ayrolles, A. Fournié, and J.-P. Soleilhavoup. 1989. High diagnostic value in theumatoid arthritis of antibodies to the stratum corneum of rat oesophagus epithelium, so-called 'antikeratin antibodies'. Ann. Rheum. Dis. 48:712-722.

31. Kirstein, H., K. Hjarvard, and T. Moørk Hansen. 1989. Antikeratin antibodies in synovial fluid in theumatoid arthritis. Acta Pathol. Microbiol. Scand. 97:185-189.

32. Vincent, C., G. Serre, J.-P. Basile, H. C. Lestra, E. Girbal, M. Sebbag, and J.-P. Soleilhavoup. 1990. Subclass distribution of IgG antibodies to the rat oesophagus stratum corneum (so-called anti-keratin antibodies) in rheumatoid arthritis. Clin. Exp. Immunol. 81:83-89.

33. Vincent, C., G. Serre, B. Fournié, A. Fournié, and J.-P. Soleilhavoup. 1991. Natural IgG to epidermal cytokeratins vs IgG to the stratum corneum of the rat esophagus epithelium, so-called 'antikeratin antibodies', in rheumatoid arthritis and other rheumatic diseases. J. Autoimmun. 4:493-505.

34. Kurki, P., K. Aho, T. Palosuo, and M. Heliövaara. 1992. Immunopathology of theumatoid arthritis. Antikeratin antibodies precede the disease. Arthritis Rheum. 35:914-917.

35. Paimela, L., M. Gripenberg, P. Kurki, and M. Leirisalo-Repo. 1992. Antikeratin antibodies: diagnostic and prognostic markers for early rheumatoid arthritis. Ann. Rheum. Dis. 51:743-746.

36. Girbal, E., and M. Sebbag, V. Gomès-Daudrix, M. Simon, C. Vincent, and G. Serre. 1993. Characterisation of the rat oesophagus epithelium antigens defined by the so-called 'antikeratin antibodies', specific for rheumatoid arthritis. Ann. Rheum. Dis. 52:749-757.

37. Simon, M., E. Girbal, M. Sebbag, V. Gomès-Daudrix, C. Vincent, G. Salama, and G. Serre. 1993. The cytokeratin filament-aggregating protein filaggrin is the target of the so-called "antikeratin antibodies", autoantibodies specific for rheumatoid arthritis. J. Clin. Invest. 92:1387-1393.

38. Hoet, R. M., and W. J. van Venrooij. 1992. The antiperinuclear factor (APF) and antikeratin antibodies (AKA) in theumatoid arthritis. In Rheumatoid Arthritis. J. S. Smolen, J. R. Kalden, and R. N. Maini, editors. Springer-Verlag, Berlin/Heidelberg. 299-318.

39. Dale, B. A., K. A. Resing, and P. V. Haydock. 1990. Filaggrins. In Cellular and Molecular Biology of Intermediate Filaments. R. D. Goldman and P. M. Steinert, editors. Plenum Publishing Corp., New York/London. 393-412.

40. Arnett, F. C., S. M. Edworthy, D. A. Boch, D. J. McShane, J. F. Fries, N. S. Cooper, L. A. Healey, S. R. Kaplan, M. H. Liang, H. S. Luthra, et al. 1988. The American Rheumatism Association 1987 revised criteria for the classification of theumatoid arthritis. Arthritis Rheum. 31:315-324.

41. Dale, B. A., A. M. Gown, P. Fleckman, J. R. Kimball, and K. A. Resing. 1987. Characterization of two monoclonal antibodies to human epidermal keratohyalin: reactivity with filaggrin and related proteins. J. Invest. Dermatol. 88:306313.

42. van Muijen, G. N. P., D. J. Ruiter, W. W. Franke, T. Achtstätter, W. H. B. Haasnoot, M. Ponec, and S. O. Warnaar. 1986. Cell type heterogeneity of cytokeratin expression in complex epithelia and carcinomas as demonstrated by monoclonal antibodies specific for cytokeratins nos. 4 and 13. Exp. Cell Res. 162:97-113.

43. Gomès-Daudrix, V., M. Sebbag, E. Girbal, C. Vincent, M. Simon, J. Rakotoarivony, M. Abbal, B. Fournié, and G. Serre. 1994. Immunoblotting detection of so-called 'antikeratin antibodies': a new assay for the diagnosis of rheumatoid arthritis. Ann. Rheum. Dis. 53:735-742.

44. Simon, M., C. Vincent, M. Haftek, E. Girbal, M. Sebbag, V. GomèsDaudrix, and G. Serre. 1995. The rheumatoid arthritis-associated autoantibodies to filaggrin label the fibrous matrix of the cornified cells but not the profilaggrincontaining keratohyalin granules in human epidermis. Clin. Exp. Immunol. 100:90-98.

45. Smith, S. A., and B. A. Dale. 1986. Immunologic localization of filaggrin in human oral epithelia and correlation with keratinization. J. Invest. Dermatol. 86:168-172.

46. Chan, K.-W. A., D. T. Felson, R. A. Yood, and A. M. Walker. 1994. The lag time between onset of symptoms and diagnosis of rheumatoid arthritis. Arthritis Rheum. 37:814-820. 